\title{
A ABORDAGEM EXPERIENCIAL EM INTERVENÇÃO PRECOCE Na formação, supervisão e intervenção
}

\author{
Gabriela Portugal e Paula Santos
}

\begin{abstract}
$\underline{\text { Resumo }}$ O sucesso da Intervenção Precoce (IP) depende dos processos vividos pelas famílias no seu percurso para se tornarem emancipadas, capazes, com poder, com sentido de controlo sobre as suas próprias vidas, educando e criando as suas crianças, participando nas comunidades em que vivem. O modelo de educação experiencial (EDEX), numa procura de apreensão do vivido da criança como ponto de referência para a intervenção, tem como objectivo último a formação de uma pessoa emancipada. Em EDEX e IP, o bem-estar emocional e a implicação das crianças / famílias são cruciais, sendo determinante a qualidade do suporte dos profissionais de educação e IP. Este suporte dinamiza-se em torno de três dimensões essenciais: sensibilidade, estimulação e promoção da autonomia das crianças/famílias. Neste quadro, torna-se imperativo o desenvolvimento de supervisão suportiva do processo de crescimento e desenvolvimento dos profissionais nas dimensões assinaladas, ela própria caracterizada por estimulação, sensibilidade e autonomia do outro.
\end{abstract}

Palavras-chave Intervenção precoce, abordagem experiencial, supervisão, estilos interactivos, estimulação, sensibilidade e autonomia.

Introdução: das relações mais precoces ao desenvolvimento... e à organização de uım programa de intervenção precoce

Pais e profissionais da infância sabem bem que os bebés necessitam de cuidados calorosos e responsivos para se desenvolverem bem. Sabem também que a aprendizagem tem lugar no contexto de importantes relações interpessoais. Se a melhor forma de ajudar crianças muito pequenas a crescerem curiosas, confiantes, aprendizes capazes, é fornecer-lhes cuidados consistentes e calorosos (que estarão na base do estabelecimento de relações de vinculação seguras com adultos significativos), a qualidade dos cuidados e relações de vinculação seguras também parece afectar as futuras capacidades de empatia, regulação emocional e controlo comportamental da criança (Shonkoff \& Phillips, 2000).

Se experiências precoces positivas têm efeitos positivos no bem-estar emocional e desenvolvimento da criança - promovendo a sua resiliência -, experiências negativas (depressão materna, toxicodependência, institucionalização,

Gabriela Portugal e Paula Santos, Departamento de Ciências da Educação da Universidade de Aveiro.

PSICOLOGIA, Vol. XVII (1), 2003, pp. 161-177 
lares caóticos, cuidados negligentes ou abusivos, ...) associam-se comummente a níveis mais elevados de problemas comportamentais e de aprendizagem no período pré-escolar e escolar, acontecendo que muitas das experiências adversas são exacerbadas pela pobreza. Admiravelmente, apesar dos efeitos adversos da pobreza, algumas crianças parecem desenvolver-se bem... A investigação indica que entre os factores de protecção que tornam estas crianças mais resilientes, a existência de uma relação de vinculação segura parece ser crucial e que os factores críticos que parecem capacitar os adultos a cuidar bem das suas crianças, mesmo em situações de pobreza, incluem: compreensão acerca do desenvolvimento da criança, apoio social e psicológico (Egeland, Carlson \& Sroufe, 1993). Famílias de risco, ou famílias que experienciam situações de grande adversidade, que usufruem de redes de apoio social, parecem ser mais capazes de assegurar um ambiente equilibrado e psicologicamente nutriente às suas crianças, facilitando, em consequência, o seu desenvolvimento.

Parece não haver dúvida de que, se todos os pais beneficiam de informações úteis e de apoios adequados à medida que educam as suas crianças, alguns necessitam de um apoio mais intenso e próximo. Os esforços para apoiar e capacitar as famílias parecem ter características "protectoras" ao facilitarem o bem-estar e desenvolvimento da própria família. Intervenções consistentes, bem concebidas, atempadas (quanto mais cedo, melhor) podem melhorar o futuro de muitas crianças consideradas em risco de desenvolvimento cognitivo, social ou emocional. Uma intervenção adequada poderá mesmo melhorar situações frequentemente consideradas inelutáveis, como perturbações genéticas ou problemas neurológicos, tais como autismo, atraso mental, ou outras situações normalmente designadas como necessidades educativas especiais (Shore, 1997). Assim, embora importe investir em vários níveis da ecologia da família (p. ex., investimento em creches de elevada qualidade), destacamos aqui a importância de programas de intervenção precoce bem sustentados e organizados.

Em Portugal, a Intervenção Precoce $(\mathbb{P})$ é um programa dirigido a crianças com menos de seis anos de idade, com deficiência ou em risco de atraso desenvolvimental, e suas famílias, procurando apoiar e promover o bem-estar e desenvolvimento físico, social, emocional e cognitivo das crianças. Envolve serviços de educação, saúde e segurança social, permitindo a criação de equipas multiprofissionais, trabalhando colaborativamente a nível local. Ao nível de cada equipa local existe um técnico de intervenção directa junto da família (a pessoa-chave para a família ou visitador domiciliário). De acordo com o despacho conjunto 891/99, em cada distrito existe uma equipa de coordenação que planifica, acompanha e avalia o desenvolvimento da IP na área geográfica da sua coordenação. Neste contexto, foi solicitada à Universidade de Aveiro - Departamento de Ciências da Educação (UA), a participação no Projecto de Intervenção Precoce de Aveiro (PIPA) ao nível da equipa de coordenação distrital, associando-se aos serviços locais de Educação, Saúde e Segurança Social, sendo-lhe atribuídas as seguintes funções:

- procurar garantir que o currículo de formação de educadores de infância inclua conhecimentos que facilitem a sua inserção e estimulem a investigação no âmbito da IP; 
- facilitar a elaboração, realização e avaliação de projectos de formação que atendam a necessidades levantadas pelos técnicos;

- criar dispositivos de investigação que acompanhem a implementação e forneçam indicadores de avaliação autoformativa dos profissionais e avaliação do impacte da IP.

A monitorização e avaliação são sem dúvida importantes elementos num programa de $\mathbb{P}$, fundamentando uma prática baseada em dados e evidências comprovadas. Um programa de IP que procura apoiar famílias e crianças em risco, promovendo o seu bem-estar e desenvolvimento, prevê implicitamente, a longo prazo, a prevenção de futuros problemas pessoais, sociais e económicos. Assiste-se hoje a uma crescente ênfase nos dados das investigações para fundamentar práticas e políticas sociais inovadoras. As noções de "o que é que funciona", "porquê" e "o que é que vale a pena fazer" (Glass, 2001) com e para as crianças e famílias, parecem ser noções-chave, quer para os investigadores, quer para os decisores e interventores. Os técnicos de intervenção directa que providenciam serviços às crianças de risco, na família e comunidade, defrontam-se amiúde com enormes desafios e tensões emocionais, solicitando referências e apoios que lhes permitam desenvolver o processo relacional subjacente à IP. Consequentemente, torna-se fundamental a existência de um quadro conceptual robusto, elemento de referência na formação, supervisão, intervenção, avaliação e interpretação dos dados. Por conseguinte, pede-se à UA que assegure o enquadramento conceptual do projecto (elegendo um modelo e identificando padrões de qualidade), que assegure formação (de acordo com o modelo conceptual eleito), e que crie mecanismos de investigação que forneçam indicadores para uma auto-avaliação formativa dos técnicos e sejam esclarecedores do impacte do PIPA no terreno.

Se a abordagem experiencial tem sido, nos últimos anos, a opção na formação inicial de educadores de infância realizada na UA, ultimamente, esta abordlagem tem-se-nos afigurado igualmente valiosa no quadro da formação, supervisão e investigação a desenvolver em IP. Na qualidade de elementos da equipa de coordenação do PIPA, vinculados à UA, pretendemos com este texto, illustrar a pertinência da abordagem experiencial em IP e desde já enquadrar conceptualmente a investigação que neste âmbito virá a ser desenvolvida.

\section{A abordagem experiencial na educação de infância}

A educação experiencial (EDEX) é resultado de uma análise crítica do ensino pré-escolar belga, no início dos anos 70, que salientava duas conclusões fundamentais: (1) frequentemente as crianças são encorajadas a expressar sentimentos que não sentem verdadeiramente, não sendo encorajadas a reconhecer e a lidar com os seus verdadeiros sentimentos; (2) apesar de uma orientação que se pretende centrada e valorativa da criança, das suas características e necessidades, vários 


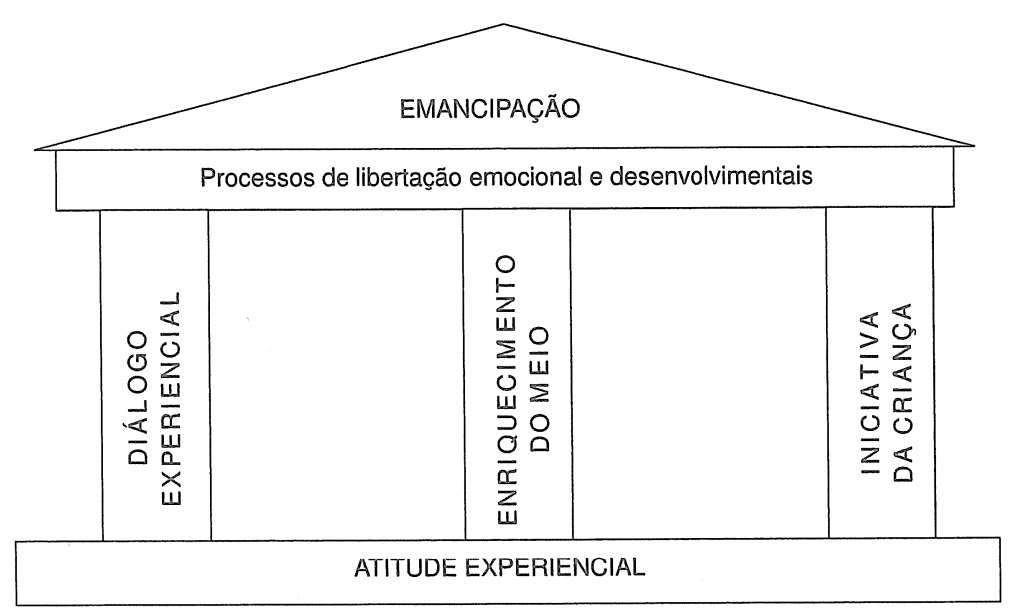

Figura 1 esquema do templo: educação experiencial

elementos traduzem uma orientação academizante, actuando o adulto como se fosse capaz de definir aquilo que as crianças apreendem ou não, como se fosse capaz de programar os processos de desenvolvimento individual. Da insatisfação relativamente às práticas pré-escolares surge cntão, em 1976, no âmbito do Research Centre for Early Childhood and Primary Education da Katholieke Universiteit of Leuven (Bélgica), o projecto EDEX, dinamizado pelo professor Ferre Laevers.

Na sua fundamentação teórica, a EDEX confere uma particular atenção aos fenómenos de mal-estar e alienação pessoal, assumindo a educação como um motor de libertação e emancipação. Na operacionalização desta preocupação, a abordagem humanista de Rogers (centrada no cliente) e de Gendlin (experiencial), articulada com alguns conceitos psicanalíticos (particularmente os desenvolvidos no âmbito da terapia pelo jogo), tiveram um importante impacte. O modelo experiencial está também profundamente imbuído de leituras construtivistas, integrando Piaget, Vygotsky e outros autores, bem como as dinâmicas das interacções e organizações humanas (tais como as contribuições ecológicas e sistémicas).

Os esforços de inovação e melhoria da qualidade da educação pré-escolar foram acompanhados por uma constante preocupação em desenvolver um quadro conceptual que enquadrasse a prática experiencial. Daí resultou, em 1979, o esquema do templo (figura 1), que combina sete conceitos de uma forma lógica e articulada (Laevers \& Van Sanden, 1997).

A base da prática experiencial é a atitude experiencial do educador, isto é, a observação do adulto para apreender o vivido da criança como ponto de referência. O adulto procura discernir - através da expressão, palavras, gestos, postura e movimento da criança - a realidade das suas significações, reconstruindo a sua experiência. Graças a este ponto de partida, os três pilares que orientam as decisões práticas, podem ser implementados. Um diz respeito à promoção da iniciativa da 
criança. Inclui um conjunto de regras que evitem danos materiais, físicos ou psíquicos, previnam o caos e garantam o direito à actividade e o máximo de liberdade para cada criança. Outro pilar mobiliza o educador para constantemente enriquecer o meio educacional através de novos materiais e actividades interessantes e estimulantes, oferecer oportunidades de exploração da realidade e funcionar como um mediador cultural. Com o último pilar, diálogo experiencial, procura-se dar uma atenção relevante à interacção entre o educador e as crianças. Este diálogo é crucial para o estabelecimento de relações interpessoais positivas, para o suporte à expressão e partilha de emoções e sentimentos, e para a estimulação à acção, requerendo uma sensibilidade particular às necessidades desenvolvimentais e emocionais da criança. Estes três pilares ou princípios servem duas categorias de processos que indicam o tipo de modificações que o educador permanentemente procura induzir: processos de libertação emocional (que se ligam com o bem-estar emocional), que são alcançados quando as crianças são ajudadas a lidar com as suas dificuldades emocionais; e processos desenvolvimentais ou criativos (que se ligam com elevada implicação), que ocorrem quando novas estruturas mentais são criadas. A perspectiva experiencial sobre os processos de desenvolvimento pode ser sumariada em dois postulados: o desenvolvimento pressupõe aprendizagens profundas ou fundamentais, e o desenvolvimento é um processo dinâmico. Ao olharmos para os efeitos da educação, podemos distinguir entre aprendizagens superficiais ou aprendizagens fundamentais. Verdadeiras modificações desenvolvimentais não podem ser vistas como uma mera adição ou colagem de elementos de conhecimento ou de competências. Pelo contrário, cada desempenho depende de uma estrutura de esquemas fundamentais que nos permite interpretar as novas situações e agir em conformidade. Na procura de compreensão de como se passa de esquemas mentais mais simples para esquemas mais elaborados, verifica-se que nas pessoas, e nas crianças em particular, existe um ímpeto desenvolvimental que as conduz a experiências que suscitam desenvolvimento. Aqui reside a legitimação da implicação. Uma pessoa implicada é conduzida pela sua necessidade exploratória que a coloca num estado psicológico favorável a aprendizagens profundas. A pessoa altamente implicada encontra-se num estado de alta concentração, conhece a intensidade da experiência, percebe-se como intrinsecamente motivada, por ela perpassa um intenso fluxo de energia e elevado nível de satisfação conectado com a satisfação do impulso exploratório. A pessoa totalmente implicada opera nos limites das suas actuais capacidades (em zona próxima de desenvolvimento).

O resultado ou objectivo último de uma educação experiencial é uma pessoa emancipada, isto é, alguém que evidencia e usufrui de saúde emocional e autenticidade, uma forte atitude exploratória, abertura ao mundo interno e externo, sentimento de pertença e de ligação, uma forte motivação para contribuir para o bem-estar universal (Laevers \& Van Sanden, 1997; Laevers, Bogaerts \& Moons, 1997; Laevers, 2000).

Sabemos que certos estilos de interacção do adulto/educador, ou certas qualidades atitudinais se relacionam com um melhor desenvolvimento e aprendizagem das crianças. As intervenções do adulto podem variar muito, dependendo da 
natureza das actividades ou das respostas e iniciativas das crianças. Podemos, contudo, discernir padrões individuais de funcionamento na forma como os educadores intervêm numa vasta variedade de situações. A escala ASOS-ECE (Adult Style Observation Schedule for Early Childhood Education, de Bertram, Laevers \& Pascal, 1996) é concebida em torno de três dimensões que corporizam os três pillares do templo: (1) estimulação (enriquecimento de actividades através de informação valiosa, ou dando impulsos que suscitem a acção, a comunicação ou o pensamento); (2) sensibilidade (dando respostas que testemunham a compreensão empática das necessidades da criança, tais como necessidade de segurança, afecto, atenção, apoio emocional, afirmação, previsibilidade e clareza...), e (3) autonomia (respeitando a iniciativa da criança, reconhecendo os seus interesses, dando-lhe espaço para experimentação, implicando-a no estabelecimento de regras e na solução de conflitos). Esta escala tem provado ser particularmente importante no campo da pesquisa educacional e no contexto da formação de educadores, ao ajudá-los a auto-analisarem os seus pontos fortes e fracos na interacção com as crianças.

\section{Conceitos nucleares em IP}

O tipo ou qualidade do investimento em IP tem sofrido alterações ao longo do tempo, dando lugar a diferentes modelos de IP (Espe-Sherwindt, 2001; Correia \& Serrano, 1998), nem sempre mutuamente exclusivos. De forma extremada, podemos distinguir:

a) IP centrada no profissional - a intervenção focaliza-se na criança e as decisões são tomadas pelos técnicos, que dispõem de conhecimentos especializados. São os profissionais que sabem o que é mellhor para a criança. A família confronta-se com a sua ignorância e incompetência, e instala-se a dependência;

b) IP aliada à família - a intervenção focaliza-se na criança mas é estabelecido um contrato com a família. Os pais participam nas actividades julgadas importantes para o desenvolvimento da criança mas é o profissional que decide como e que actividades serão implementadas com a família;

c) IP focalizada na familia - a intervenção focaliza-se na família. Não existe, contudo, verdadeira colaboração e aceitação dos valores, interesses e referências da família. De facto, os profissionais desejariam homogeneizar todas as famílias, fazendo confluir as suas necessidades e objectivos com os identificados pelos profissionais. Grande parte do tempo, os profissionais tentam ou desejam modificar as familias com vista a transformá-las em famúlias iguais às suas... Existe o risco de se esquecer que o sentido da intervenção é o bem-estar e desenvolvimento da criança;

d) IP centrada na famúlia - a intervenção implica colaboração com a família num contexto de desenvolvimento de relações positivas, respeitadoras $€$ 
igualitárias. Inclui resolução de problemas e tomada de decisões partilhadas com vista à promoção do desenvolvimento e bem-estar da criança.

Nesta linha de pensamento, Doan-Sampon, Wollenburg e Campbell (1999) descrevem como conceitos e práticas nucleares em IP, o seguinte:

- IP centrada na família - significa que a IP é guiada pela família. A intervenção respeita não apenas o desenvolvimento da criança mas também a definição e percepção da família sobre o que é considerado importante.

- IP ecológica - a IP tem em consideração o contexto mais vasto da família e comunidade, considerando que os diferentes níveis ecológicos interagem $e$ influenciam-se mutuamente, e não podem ser pensados isoladamente. A cultura da família e o ambiente influenciam a definição dos objectivos da intervenção e os meios para os atingir.

- IP focalizada nas relações - as relações pais-criança são o coração da IP. Pais e crianças podem experienciar dificuldades no desenvolvimento de relações calorosas, positivas e responsivas. O desafio, nestas circunstâncias, é o de evidenciar e nutrir padrões interactivos adequados e gratificantes, facilitando a sua maior ocorrência e minimizando interacções menos adequadas. Neste processo, se a facilitação da construção de uma relação pais-criança positiva confere forma e sentido à intervenção, o desenvolvimento de uma relação de confiança entre o técnico e a família torna-se primordial.

- IP baseada nas forças - a IP não pode ser intrusiva ou ajuizadora dos padrões de interacção familiar. O papel do profissional é o de, com a família, descobrir forças e capacidades, providenciar informação necessária e apoiar os esforços da família para optimizar os avanços desenvolvimentais da criança e as suas competências parentais.

- IP reflexiva - o reconhecimento do sistema complexo de variáveis que intervêm em IP implica que o técnico colha, ao longo do tempo, informações sobre a criança, as interacções no seio da família e com a comunidade. Comunicação permanente e reflexão asseguram a flexibilidade e fluidez da intervenção à medida que novas informações são incorporadas no plano da família, de acordo com a alteração das prioridades e percepções da família.

Ainda que possa haver uma variabilidade substancial na natureza e abordagens dos serviços de IP de contexto para contexto, hoje em dia existe grande concordância quanto à necessidade de realizar intervenções que considerem as necessidades da criança e da família, formalizadas através de um plano individualizado de apoio à família (PIAF), e quanto ao reconhecimento da importância de envolver as famílias em todas as dimensões do programa (Doan-Sampon, Wollenburg \& Campbell, 1999), nomeadamente no que respeita à:

a) avaliação (recolhà e registo de informação);

b) tomada de decisões (definição de objectivos e finalidades funcionais);

c) implementação da intervenção; 
d) monitorização do programa (avaliação);

e) definição de novos objectivos.

Traballhar com famílias e crianças em risco de atraso desenvolvimental, frequentemente convivendo com situações de doença, desestruturação familiar e pobreza severa, evoca facilmente fortes respostas emocionais por parte dos visitadores domiciliários, abalando os seus valores e crenças pessoais, e requerendo o uso de competências que poderão não ter sido desenvolvidas em formação ou experiências de trabalho prévias (Copa et al., 1999). O impacte positivo da intervenção depende dos processos vividos pela família, no seu desejo de se tornarem capazes, com poder, com um sentido de controlo sobre a sua própria vida, criando as suas crianças, participando na comunidade, experienciando sentimentos de bem-estar emocional e implicação. A experiência indica que dar oportunidade ao técnico de intervenção precoce directa de reflectir sobre o seu trabalho, pensar e falar sobre as interacções com as crianças e familias, num contexto de reuniões de trabalho psicologicamente confortáveis e seguras, sob orientação de um supervisor, é crucial para o sucesso da intervenção.

Paula: A minha experiência de dez anos como visitadora domiciliária (VD), formanda e formadora no campo da IP — trabalhando com crianças dos zero aos três anos em risco de atraso de desenvolvimento e suas famílias, e técnicos de IP de várias disciplinas -, ensinou-me algumas das coisas mais importantes na minha vida, tanto na dimensão profissional, como na pessoal. Essencialmente, senti a necessidade de ver, pensar e sentir como se eu própria fosse a família da criança com necessidades especiais com quem estava a interagir e, num processo paralelo, também compreender a experiência dos outros técnicos de IP.

Desde o início, senti o processo de empatia com as famílias como algo inevitável ao crescimento da relação. Só ele tornava possível perceber e partilhar com a família, o que eu julgava ter sentido e ser pensado como útil pela família, naquele particular momento das suas vidas, e compreender o seu saber sobre a vida, sobre ser pai/mãe, ser parte de uma comunidade...

Durante esse tempo, primeiro como VD e formanda, mais tarde também como supervisora e formadora, aprendi a valorizar a capacidade de ser uma boa ouvinte, descobrindo as forças e factores positivos nas famílias e nos técnicos, confiando, refraseando o que as pessoas me diziam - oferecendo a oportunidade de compararem a minha compreensão da sua mensagem, com aquela que efectivamente queriam transmitir - , eventualmente enriquecendo o diálogo com algo novo... Numa contínua procura do meu lugar nas constelações relacionais em que participava, dependendo o meu ser e estar, dos momentos actuais que cada participante vivia, e do modo como o grupo construía progressivamente a sua realidade...

Quando comecei a trabalhar em IP, sentia que a minha formação inicial e experiência, o meu conhecimento disciplinar (em educação de infância e educação especial), não 'me tinham preparado para trabalhar com famílias - definitivamente, não numa abordagem centrada na família; e ouvi muitas, muitas vezes, outros técnicos de IP partilhando o mesmo sentir. 
Creio que é difícil para nós ultrapassar o modo tradicional de sermos educadores, em modelos em que o poder, as oportunidades de tomada de decisão, estão muito nas mãos do técnico, e muito pouco nas mãos, coração e cabeça do "cliente", quer ele seja uma criança, uma família, uma comunidade, ou um outro profissional de IP.

Quando conheci o trabalho desenvolvido pelo Centre for Experiential Education (Lovaina - Bélgica), senti-me confortada e entusiasmada. A abordagem experiencial representava o enquadramento de que necessitava para encaixar o que havia aprendido ao longo das minhas anteriores experiências enquanto estudante, técnica, educadora e pessoa. O modelo conceptual da educação experiencial permitiu-me integrar os meus conhecimentos e experiências anteriores, bem como todos os que construí a partir daí, actuando como fundação e sustentando a minha construção enquanto pessoa e profissional.

\section{$\mathbb{E D E X}$ e IP}

O essencial da IP é comum à EDEX: dar poder e capacitar o "sujeito" para crescer e desenvolver-se, experienciando sentimentos de bem-estar emocional e implicação. Em ambos os casos existe um efeito reflexo: se se pretende promover a confiança, capacitar e dar poder a alguém, necessitam os próprios profissionais de se sentir confiantes, com poder e capazes.

O modelo experiencial constitui um quadro teórico que oferece uma forma mais respeitosa de sentir, pensar e fazer coisas em educação de infância e IIP. Caracteriza-se por respeito, atenção e confiança - centrado na criança/família, procurando o adulto perceber a experiência da criança/família, reconstruindo através da sua expressão, palavra, gesto... o seu significado. É a experiência do outro o ponto de referência para a acção ou intervenção do profissional, que se corporiza em torno de três dimensões: iniciativa da criança/familia (autonomia), enriquecimento do meio (estimulação) e diálogo experiencial (sensibilidade traduzível em empatia, aceitação e autenticidade). Procura induzir processos de libertação emocional e desenvolvimentais (bem-estar emocional e implicação) que, por sua vez, asseguram o desenvolvimento de uma pessoa emancipada, ou seja, alguém que está bem consigo próprio, que não tem de dispersar energias em sentimentos de depressão, alienação, impotência, ... característicos de quem viveu e integrou mal certas experiências emocionais. A pessoa emancipada é a pessoa que estabelece um bom "contacto" consigo própria, com os outros, a sociedade, a natureza, o universo... Sabe apreciar aquilo que a vida lhe oferece, tomar iniciativas, estabelecer relações de intimidade, ajudar outros a crescer e a emancipar-se...

O paralelismo entre uma prática de educação de infância centrada na criança (experiencial) e uma prática de IP centrada na família torna-se mais claro quando adoptamos as dimensõ̀es interpessoais previstas em Adult Style Observation Schedule - ASOS (Bertram, Laevers, \& Pascal, 1996; Laevers, Bogaerts, \& Moons, 1997; Laevers, 2000) como indicadores de desenvolvimento profissional e pessoal, 
Quadro 1 Dimensões interpessoais dos profissionais de educação de infância e intervenção precoce

\begin{tabular}{l|l|l}
\hline & Profissional El & Profissional IP \\
\hline Estimulação & $\begin{array}{l}\text { É demonstrada em impulsos abertos que } \\
\text { geram uma cadeia de acções nas crianças e } \\
\text { fazem a diferença entre alta e baixa } \\
\text { implicação. Incluem: sugerir actividades às } \\
\text { crianças; oferecer-lhes materiais que } \\
\text { enriqueçam a actividade em curso; convidar } \\
\text { as crianças a comunicar; confrontá-las com } \\
\text { questões que promovam raciocínio e dar-lhes } \\
\text { informação que possa cativar a sua mente. } \\
\text { (in Laevers, 2000) }\end{array}$ & $\begin{array}{l}\text { Criando oportunidades para as famílias } \\
\text { construírem conhecimento sobre si próprias } \\
\text { enquanto pessoas (descobrindo as suas } \\
\text { próprias forças e capacidades e as das suas } \\
\text { crianças), as comunidades em que vivem } \\
\text { (recursos disponíveis) e as dinâmicas } \\
\text { capazes de apoiar o seu crescimento e } \\
\text { desenvolvimento (acções, estratégias e } \\
\text { meios). } \\
\text { (in Doan-Sampon et al., 1999) }\end{array}$ \\
\hline Sensibilidade & $\begin{array}{l}\text { É demonstrada através de respostas que } \\
\text { evidenciam compreensão empática das } \\
\text { necessidades básicas da criança, tais como, } \\
\text { a necessidade de segurança, afecto, } \\
\text { atenção, afirmação, clareza e suporte } \\
\text { emocional. } \\
\text { (in Laevers, 2000) }\end{array}$ & $\begin{array}{l}\text { Compreendendo os sentimentos e } \\
\text { pensamentos das famílias, como se fossem } \\
\text { os seus próprios, e dando a conhecer às } \\
\text { famílias que são compreendidas e } \\
\text { incondicionalmente apreciadas, criando o } \\
\text { espaço de uma relação de confiança, } \\
\text { respeitando os seus próprios valores e } \\
\text { crenças. } \\
\text { (in Doan-Sampon et al., 1999) }\end{array}$ \\
\hline Autonomia & $\begin{array}{l}\text { Significa respeitar o sentido de iniciativa das } \\
\text { crianças identificando e indo ao encontro dos } \\
\text { seus interesses; dando-lhes espaço para } \\
\text { experimentação; deixando-as decidir como é } \\
\text { realizada uma actividade e quando um } \\
\text { produto está acabado, e implicando-as no } \\
\text { estabelecimento de regras e na resolução de } \\
\text { conflitos. } \\
\text { (in Laevers, 2000) }\end{array}$ & $\begin{array}{l}\text { Significa apoiar os membros da família na } \\
\text { sua iniciativa para conceber e implementar } \\
\text { um projecto de vida (definindo os resultados } \\
\text { que querem obter e os melhores meios para } \\
\text { ofazer). } \\
\text { (in Doan-Sampon et al., 1999) }\end{array}$ \\
\hline
\end{tabular}

amparando a reflexão e auto-avaliação (quadro 1). Efectivamente, este instrumento de leitura do estilo interactivo do adulto assume-se como particularmente poderoso no processo de capacitação dos profissionais para desenvolverem atitudes sensíveis, estimulantes e promotoras de autonomia (sempre conectadas com um modelo ecológico, centrado na pessoa, reflexivo, baseado nas forças e focalizado nas relações).

\section{Da supervisão às práticas reflexivas experienciais}

No mundo da prática profissional com crianças e suas famílias, a supervisão providencia oportunidades regulares aos técnicos, mais ou menos experientes, de reflexão conjunta sobre as suas vivências profissionais. Tal como as famílias necessitam de suporte, informação, atenção e respeito no sentido de se tornarem mais confiantes e competentes, também os profissionais necessitam de relações suportivas, sob forma de supervisão, com vista a que eles próprios se sintam com poder e capazes. 
Como Fenichel (1999) afirma, uma supervisão eficaz inclui algumas características essenciais: reflexão, colaboração e regularidade. "Reflection can be thought of as both the means and the end of the process of supervision. Reflection involves stepping back from the immediate, intense experience of hands-on-work... The supervisor offers an enlarged perspective, another pair of eyes, a mirror... Part of the process of developing a professional identity involves recognizing the need to enlarge one's own knowledge, skills and sensitivity" (p. 13). A reflexão envolve examinar os sentimentos experienciados, valores e teorias pessoais. Em suma, a reflexão envolve conceptualização contínua sobre o que cada um observa e faz. Trabalhar em contextos familiares muito diversos, enfrentando desafios emocionais e intelectuais, pode ser muito perturbador. Neste quadro, a experiência da supervisão tem sido descrita como "having a friend on a difficult journey" (p. 14), pois poucos serão os que gostarão de viajar sós em território desconhecido ou obscuro e, nesse sentido, uma relação de supervisão colaborativa e duradoira, nutriente e gratificante, é um factor extremamente reconfortante.

Obviamente, o desenvolvimento de uma relação de supervisão com as características descritas requer regularidade (tempo para reflectir, tempo para colaborar e, acima de tudo, tempo para estabelecer uma relação de confiança).

Embora diferentes estratégias possam ser implementadas no contexto de uma relação de supervisão, elegemos os estudos de caso e discussões em grupo (Shulman, 1999), e as dinâmicas de auto-avaliação, como particularmente elicitadoras de desenvolvimento pessoal e profissional, quer em educação, quer em IP.

\section{Estudos de caso e discussões em grupo}

Podemos aprender imenso a partir da prática. As histórias, os incidentes críticos, os casos são importantes contributos para o estreitamento entre a teoria e a prática. No apoio aos técnicos, os supervisores necessitam de conhecer as suas histórias, perspectivas e realidades. A discussão de casos no contexto da supervisão e de reuniões de grupo estimula a reflexão colaborativa na exploração de problemas complexos para os quais não existem teorias explícitas ou respostas simples (Shulman, 1999): configura a génese e análise de diferentes pontos de vista; facilita o desenvolvimento de competências de resolução de problemas; permite um sentido de colegialidade e de compreensão partillhada numa comunidade de aprendizes; estimula uma atitude introspectiva relativamente à própria prática que fundamenta a auto-análise / auto-avaliação.

\section{Auto-análise/auto-avaliação}

É comum a dificuldade de questionamento das próprias práticas. Frequentemente, os profissionais do humano explicam os problemas e dificuldades com referência às características das crianças, famílias, cultura, mentalidades, organização, programas, políticas sociais e educativas, etc., muito raramente referenciando as 
práticas e comportamentos dos profissionais como potenciais ou possíveis elementos bloqueadores de um processo de desenvolvimento e aprendizagem. Se todos trabalham da melhor forma que sabem e podem, torna-se importante desenvolver uma culltura de reflexão e auto-avaliação, uma cultura de modéstia e de humildade. Os profissionais devem perceber o impacte das suas acções e verbalizações nas crianças e famílias, e compreender que se as crianças ou as familias são "difíceis", pouco receptivas, desinteressadas, o profissional tem de lidar com isso não como um problema que está para além do seu controlo, inerente à criança, família ou comunidade, mas como um problema seu, permanentemente ensaiando novas abordagens e alternativas, respeitando e confiando nas crianças e suas famílias. A assumpção da sua responsabilidade em todo este processo requer um permanente questionamento dos profissionais relativamente ao seu desempenho, caracteristicas e estilo interactivo.

No contexto das interacções individuais com as famílias, é suposto efectuarem-se avaliações, determinar finalidades e objectivos, implementar, monitorizar e avaliar as intervenções, e subsequentemente determinar novos objectivos... Sensibilidade, estimulação e autonomia são dimensões cruciais no envolvimento das famílias ao longo de todas as fases do programa.

Considerando os processos de identificação de objectivos da intervenção e de avaliação da criança, podemos imaginar situações como as que se descrevem nos quadros 2 e 3 (adaptados de McWilliam \& Winton, 1991) e ligá-las, com maior ou menor facilidade, às dimensões estimulação, sensibilidade e autonomia. De facto, a complexidade da realidade não permite captá-la, sem a distorcer, num modelo ou esquema tridimensional organizado de forma estática. A realidade é um todo complexo e orgânico que vai muito para além do nosso conhecimento, escapando às nossas visões parciais. Frequentemente, diferentes dimensões coexistem na mesma situação, embora talvez possamos vislumbrar a proeminência de uma em relação a outras. Diferentes perspectivas, diferentes contextos, diferentes famílias poderão determinar análises e respostas diferentes. $O$ valor da abordagem aqui apresentada tem sobretudo a ver com a potencial contribuição para a reflexão, discussão e auto-avaliação, em contexto de supervisão, na procura da melhoria da qualidade no que é oferecido às famúlias e crianças.

A atitude experiencial em IP não é apenas importante ao nível da intervenção directa com a família e crianças mas também ao nível da supervisão, sendo fundamental estar em contacto com as experiências emocionais e cognitivas dos técnicos de IP. Uma adaptação do esquema do templo pode lançar luz sobre esta ideia (figura 2).

A supervisão em IP, caracterizada por colaboração (em resultado do estabelecimento de relações de confiança e de tempo conjunto consistente) e reflexão sobre as práticas, não tem lugar se o supervisor não estiver realmente em contacto com as experiências internas do técnico, prestando atenção aos seus sentimentos e pensamentos, reconstruindo as suas experiências, examinando as suas situações e problemas através das suas perspectivas. O que pretende o supervisor que aconteça com as suas intervenções? Bem-estar emocional, particularmente consubstanciado em confiança, e implicação, mais especificamente um sentido de competência e de 
Quadro 2 Sensibilidade, estimulação e autonomia na identificação de objectivos em IP

\begin{tabular}{|c|c|c|c|}
\hline No processo de identificação de objectivos de intervenção, o profissional de IP... & Sens & Est & Aut \\
\hline $\begin{array}{l}\text {... compreende a cultura e sistema de valores da f́amília, aceitando-os mesmo quando estes } \\
\text { colidem com os seus. }\end{array}$ & $x$ & & \\
\hline $\begin{array}{l}\text {... apoia os pais na identificação de objectivos, utilizando conceitos, termos e questões com } \\
\text { os quais estes se podem identificar (ex.: relacionando com sentimentos, preocupações, } \\
\text { rotinas diárias, relações, ...), e não tanto terminologia profissional (ex.: desenvolvimento } \\
\text { cognitivo e social, motricidade grossa, autonomia, ...). }\end{array}$ & & $x$ & \\
\hline $\begin{array}{l}\text {... refreia o seu ímpeto para "aconselhar", a não ser que tenha a certeza que isso é desejado } \\
\text { pela família. }\end{array}$ & & & $x$ \\
\hline $\begin{array}{l}\text {... obtém informação sobre o tipo, a quantidade, a adequabilidade dos apoios informais que a } \\
\text { familia recebe (ex.: amigos, família extensa, ...). }\end{array}$ & & $x$ & \\
\hline $\begin{array}{l}\text {... obtém informação dos pais sobre aspirações futuras, desejos, objectivos a longo prazo } \\
\text { (para a criança, para eles próprios, para toda a família). }\end{array}$ & & $x$ & \\
\hline$\ldots$ assegura aos pais que compreende e acredita naquilo que eles the dizem. & $x$ & & \\
\hline $\begin{array}{l}\text { apoia as famílias na ident } \\
\text { óprios, trabalhando conjun }\end{array}$ & & & $x$ \\
\hline
\end{tabular}

Quadro 3 Sensibilidade, estimulação e autonomia na avaliação da criança em IP

\begin{tabular}{|c|c|c|c|}
\hline No processo de avaliação da criança, o profissional de IP... & Sens & Est & Aut \\
\hline $\begin{array}{l}\text {... prepara os pais para a avaliação da criança (informando-os do que se tratará, } \\
\text { fornecendo-lhes uma grelha de avaliação, preparando-os para se encontrarem com outros } \\
\text { membros da equipa). }\end{array}$ & & $x$ & \\
\hline $\begin{array}{l}\text {... atenta e claramente (em linguagem compreendida pelos pais), explica o propósito, } \\
\text { conteúdo e sistema de cotação dos instrumentos de avaliação antes da sua administração. }\end{array}$ & $x$ & & \\
\hline $\begin{array}{l}\text {... conversa com os pais ao longo da avaliação da criança (ex.: explicando o objectivo e } \\
\text { significado dos itens do teste, comentando o desempenho da criança). }\end{array}$ & & $x$ & \\
\hline $\begin{array}{l}\text {... permite que os próprios pais administrem itens do teste ou pede-lhes sugestões sobre } \\
\text { como obter o melhor desempenho da criança (ex.: demonstrando-lhes como fazer). }\end{array}$ & & & $x$ \\
\hline $\begin{array}{l}\text {... acredita nos pais quando estes referem que a criança é capaz de um determinado } \\
\text { desempenho, que em situação de teste não foi observado. }\end{array}$ & $x$ & & \\
\hline $\begin{array}{l}\text {.. enfatiza aos pais sobretudo aquilo que a criança é capaz de fazer e nã } \\
\text { ela não é capaz. }\end{array}$ & & $x$ & \\
\hline
\end{tabular}

poder para enfrentar desafios, com vista a atingir a emancipação dos principais sujeitos envolvidos em todo o processo. Como pode o supervisor atingir estes objectivos? Sendo sensível, estimulante e promovendo a autonomia dos supervisandos. 


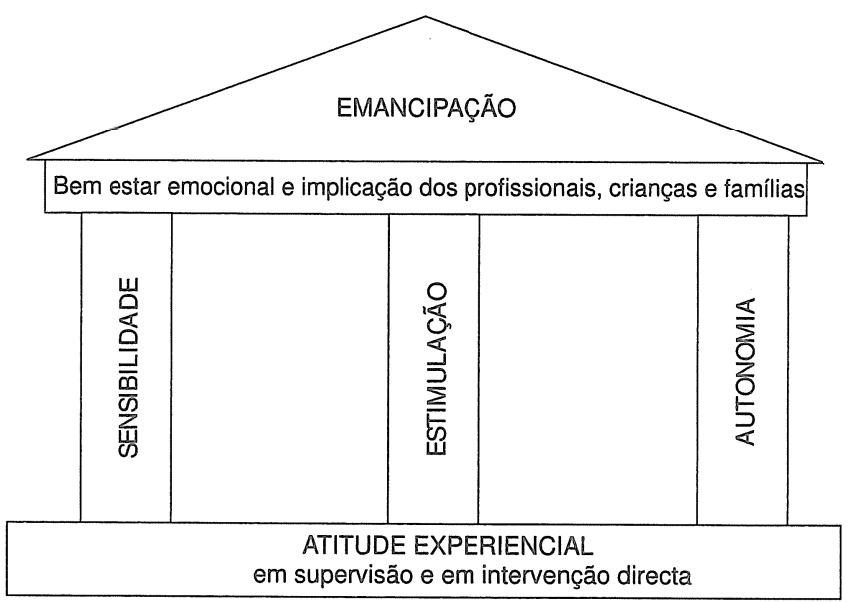

Figura 2 osquema do templo: abordagem experiencial em IP

\section{Conclusão em discurso directo... ou um caso para estreitamento entre a teoria e a prática}

Paula: Enquanto visitadora domiciliária de crianças e famílias em situação de risco, senti muitas vezes urgência de actuar no limite máximo das minhas capacidades um forte desafio de pôr ao dispor da acção todo o meu saber, toda a minha capacidade de intervenção. Quando se trabalha com pessoas nestas circunstâncias e se lida com os seus problemas, cedo se compreende que não há certezas, não há apenas um modo de fazer as coisas. Podemos simplesmente criar o espaço para uma relação nutriente, oferecendo às pessoas a oportunidade de escolher uma via que seja, no momento, a mais respeitadora dos seus próprios valores e crenças, de modo que possam implicar-se e encontrar equilíbrio e bem-estar nas suas vidas. Esta não é uma tarefa fácil para um técnico que está só. Um tarefa destas exige uma abordagem não só multisserviços e multiprofissional, mas transdisciplinar. Então, a única maneira que conheço para assimilar os valores nucleares a respeitar em IP, sendo uma profissional de IP que realiza uma intervenção centrada na família, ecológica, baseada nas forças, focada nas relações e reflexiva, é participando num grupo reflexivo, de várias pessoas com diferentes backgrounds, partilhando as mesmas metas, crenças e valores, dinamizado por um supervisor experiencial. Para mim, isto significa um supervisor que empatiza com os sentimentos e pensamentos dos técnicos de IP, dando-lhes a conhecer que estão a ser compreendidos, criando assim um espaço de liberdade, tranquilidade e segurança, promovendo abertura a corações e mentes, partilha de medos, dúvidas e alegrias experienciados ao trabalhar com as crianças e famílias. Significa também alguém que observa e aprende com o saber do técnico, escutando activamente as suas histórias e ajudando-o a construir pontes entre os problemas e o conhecimento disponível no grupo, provendo um movimento de scaffolding à emergência de um saber e 
compreensão únicos, transdisciplinares. Finalmente, significa apoiá-los na procura de uma via para desenvolverem a sua própria autonomia, aprendendo como escutar as famílias, crianças e colegas, a evocar conhecimento, a ligar eventos, assunções, ideias, e a ser proactivos.

Para mim, foi crucial ter tempo, de um modo consistente, com os elementos do meu grupo e a minha supervisora. Eu precisava da certeza de que, todas as semanas ou todos os quinze dias (um período de tempo maior entre as reuniões resulta em demasiada distância dos eventos experienciados), podia contar com o apoio do meu grupo e da minha supervisora. Isto representa uma componente de equilíbrio e tranquilidade, também.

Num efeito sinergético, eu sentia (sinto) que o experienciar de uma tal situação de supervisão me capacitava para ser mais sensível, estimulante e capaz de promover a autonomia das famílias.

Eu estava a trabalhar junto com a família da Sara - mãe e pai - há 3 meses. Encontrávamo-nos numa sala da nossa sede; os pais tinham declarado, no início da nossa relação, que não queriam o apoio de IP em sua casa. ASara estava a evoluir muito bem: ela estava a resolver todas as tarefas desenvolvimentais que tínhamos planeado e, o que era melhor, estava feliz, relacionando-se com os seus pais com uma alegria crescente, o que podíamos ver pela sua expressão, atitudes, movimento e brincar. Então, por altura do Natal, os pais disseram-me: "A partir de agora, gostaríamos que passasse a vir a nossa casa... Sabe, quando nos perguntou o que preferiríamos, se encontrarmo-nos em nossa casa ou noutro local, nós imaginámos uma brigada a entrar em nossa casa todas as semanas..."

Senti que estes pais tinham verbalizado o que eu própria sentiria se fosse receber visitas domiciliárias de um técnico que não conhecesse antes. Acredito que eu não permitiria que uma pessoa desconhecida entrasse (talvez deva dizer "se intrometes$\mathrm{se}^{\prime \prime}$ ?) e agisse na minha casa e na minha família, assim, sem mais nem menos! Especialmente se eu já tivesse passado por situações difíceis com "peritos", ou se estivesse a lidar com sentimentos e pensamentos negativos acerca das necessidades especiais da minha criança.

O que iria essa pessoa pensar de mim e da minha família? O que saberia ela do que é ter uma criança com deficiência? Iria ela avaliar-me, fazer juízos de valor acerca de mim e da minha família?

Eu precisaria de interagir com essa pessoa, de experienciar situações de relação e, com o tempo, se me sentisse segura, relaxaria numa relação de confiança, buscando o apoio de que precisava, de facto... Seria importante criar um espaço confortável para nós, onde me sentisse à vontade, apreciada, valorizada - mesmo que os meus próprios valores, crenças e modo de viver o dia-a-dia fossem muito diferentes dos desse/a profissional com quem eu estava a interagir - , capaz e com poder. Nessas condições, penso que seria capaz de descobrir as minhas forças, quaisquer que elas fossem, e construir novas, num processo contínuo de descoberta de capacidades e necessidades do meu filho/a, e experienciando esses momentos brilhantes, mágicos, em que eu e o meu filho/a realmente nos encontrássemos num encaixe perfeito, num processo de descoberta mútua, agindo no melhor de nós próprios...

Interagindo com Sara e os seus pais durante mais de dois anos, senti-me 
próxima deles, partilhando as nossas forças, os nossos sentimentos e pensamentos, as nossas dúvidas, ... E nós construímos um projecto - um sonho? - sobre o bem-estar e desenvolvimento da Sara, o bem-estar e crescimento deles enquanto família, e o meu próprio bem-estar e desenvolvimento profissional e pessoal. E demos-lhe vida nas situações do dia-a-dia que os pais da Sara lhe ofereciam... Eles encontraram tranquilidade e harmonia na relação com a sua filha, sendo capazes de a incluir, com as suas capacidades e dificuldades, no seu projecto de vida, sentindo-se emancipados...

\section{Referências}

Bertram, T., Laevers, F., \& Pascal, C. (1996). L'étude de la qualité de l'interaction adulte-enfant dans le pré-scolaire: "Le schéma d'observation du style de l'adulte". In S. Rayna, F. Laevers, \& M. Deleau (Eds.), L'Education préscolaire, quels objectifs pédagogiques? Paris: INRP e Nathan.

Copa, A., Lucinski, L., \& Wollenburg, K. (1999). Promoting professional and organizational development: A reflective practice model. Zero to Three, August/September, 3-9.

Correia, L., \& Serrano, A. M. (1998). Envolvimento parental em intervenção precoce. Das prúticas centradas na criança às práticas centradas na família. Porto: Porto Editora (col. Educação Especial).

Doan-Sampon, M., Wollenburg, K., \& Campbell, A. (1999). Growing: Birth to three. Piecing it all together (The Portage Project, CESA 5). Wisconsin, USA: Portage.

Egeland, B. E., Carlson, E., \& Sroufe, L. A. (1993). Resilience as process. Development and psychopathology, 5, 517-528.

Espe-Sherwindt, M. (2001, Fevereiro). O PIAF: Mais do que um pedaço de papel. Conference and Workshop apresentados na Universidade de Aveiro.

Fenichel, E. (ed.) (1999). Learning through supervision and mentorship to support the development of infants, toddlers and their families: A source book. Washington, DC: Zero to Three, National Center for Infants, Toddlers and Families.

Glass, N. (2001). What works for children - the political issues. Children \& Society, 15 (1), pp. 14-20.

Laevers, F., \& Van Sanden, P. (1997). Pour une approche expérientielle au niveau préscolaire. Livre de base (col. Education et Enseignement Expérientiel, n. ${ }^{\circ}$ ). Lovaina: Centre pour un Enseignement Expérientiel.

Laevers, F. (2000). Forward to basics! Deep-level-learning and the experiential approach. Early Years, 20 (2), pp. 20-29.

Laevers, F., Bogaerts, M., \& Moons, J. (1997). Experiential education at work: A setting with 5-year olds (video and manual). Lovaina: Centre for Experiential Education.

McWilliam, P. J., \& Winton, P. (1991). Brass Tacks. Chapel Hill, NC: The Frank Porter Graham Child Development Center/The University of North Carolina.

Shonkoff, J. P., \& Phillips, D. A. (Eds.) (2000). From neurons to neighborhoods: The science of early childhood development. Washington, DC: National Academy Press. 
Shore, R. (1997). Rethinking the brain: New insights into early development. Nova Iorque: Families and Work Institute.

Shulman, J. (1999, Dezembro). Teaching cases: New approaches to the pedagogy of teacher education. Workshop WestEd: Improving education through research, development and service. Aveiro: Universidade de Aveiro.

An experiential approach in early intervention: in training, supervision and intervention (abstract) Early Intervention (EI) is a family centred process, having as ultimate desired outcome, the development and well being of 0-6 children at risk of developmental delay (due to established, biological or environmental factors). Its success depends on the processes lived by their families, on their strive to become capable, empowered, in control of their own lives, raising their children, participating in the communities they live in, experiencing feelings of emotional well being and involvement. In order to support families in their strive to acquire all those strengths that make them families, the role played by professionals capable of being sensitive, stimulating and promoting autonomy of families is crucial. Scaffolding the professionals on their strive of acquiring competencies to develop the relational process underlying EI, we present a training, supervision and evaluating model of EI based on an experiential approach. 